\title{
Neustart als Chance
}

\section{Ankündigung und Aufruf zur Vortragseinreichung}

\section{Dessauer Gasmotoren-Konferenz}

Dessau-Roßlau, 06. und 07. Mai 2021

Liebe Leserin, lieber Leser,

die Corona-Krise reduziert die globalen $\mathrm{CO}_{2}$-Emissionen. Bei $\mathrm{NO}_{\mathrm{x}}$ und Feinstaub ist das aber nicht überall der Fall. In den letzten beiden Jahren war die Debatte um Fahrverbote eines der Top-Themen. Dabei bestimmten Akteure mit teilweise rudimentärer Fachkenntnis die öffentliche Meinung. Der Autoindustrie wurde aus teils nachvollziehbaren Gründen, unabhängigen Experten aber oft aus ideologischen Gründen die Berechtigung abgesprochen, an der Zukunft der Mobilität mitzuwirken. Fahrverbote aufgrund des Überschreitens von $\mathrm{NO}_{\mathrm{x}^{-}}$und Feinstaubbelastungen der Luft in urbanen Ballungsräumen schienen das Gebot der Stunde und wurden von Umweltverbänden teils gerichtlich durchgesetzt. Die Corona-Krise bietet nun die Möglichkeit, die Wirksamkeit solcher Fahrverbote zu überprüfen, denn der Individualverkehr ging schließlich erheblich zurück.

Ein Blick auf zwei Landeshauptstädte: Die Messwerte für Stuttgart zeigen, dass vor dem Lockdown die Luft dort oft sauberer war als währenddessen. In Stuttgart-Bad Cannstatt lagen die $\mathrm{NO}_{\mathrm{x}}$-Werte im Zeitraum seit dem 16. März an mehr Tagen über $50 \mathrm{mg} / \mathrm{m}^{3}$ Luft als vorher. Bei Feinstaub zeigt sich ein ähnliches Bild. In Mainz sollte aus Gründen der Luftreinhaltung die komplette Rheinachse für Dieselfahrzeuge einschließlich Euro 5 gesperrt werden. Das Umweltdezernat hält an den Plänen fest, allerdings sträuben sich sowohl Opposition als auch Koalition und fordern die Offenlegung der Messwerte. Die Beispiele zeigen, wie auch die Situation in Berlin, dass moderne Verbrennungsmotoren mit funktionierender Abgasnachbehandlung keinen so starken Einfluss auf die Luftqualität in Ballungsräumen zu haben scheinen wie bisher angenommen; und dass andere Verursacher und das Wetter eine deutlich größere Rolle spielen.
Bundeskanzlerin Merkel und Bundesumweltministerin Schulze stellten sich auf dem Petersberger Klimadialog hinter den „Green Deal“ der EU und forderten, der wirtschaftliche Neustart nach Corona müsse ökologisch orientiert sein. Das ist prinzipiell richtig und gut - wenn es konsequent und in Bezug auf Mobilität technologieoffen und mit großer Fachkenntnis umgesetzt wird. Sollen Klimaschutz und Luftreinhaltung global und nachhaltig erfolgen, dann ist E-Mobilität nicht der Weisheit einziger Schluss, und es führt kein Weg an synthetischen Kraftstoffen vorbei. „Beim Klima kennen wir den Impfstoff schon“, sagte Schulze. Genau, und ein wichtiger Grundstoff für diesen Impfstoff sind synthetische Kraftstoffe aus nachhaltigen Quellen, eingesetzt in einer sauberen, modernen Bestandsflotte.

Übrigens: Die MTZ belegte beim renommierten deutschen Wettbewerb „Fachmedium des Jahres“ 2020 in ihrer Kategorie einen hervorragenden 2. Platz.

Viel Vergnügen beim Lesen dieser Ausgabe der MTZ.

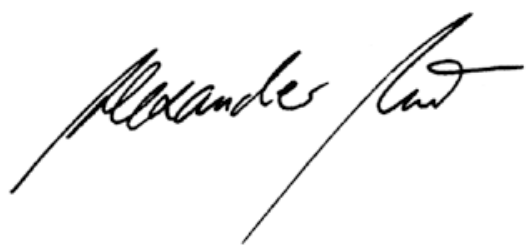

Dr. Alexander Heintzel

Chefredakteur

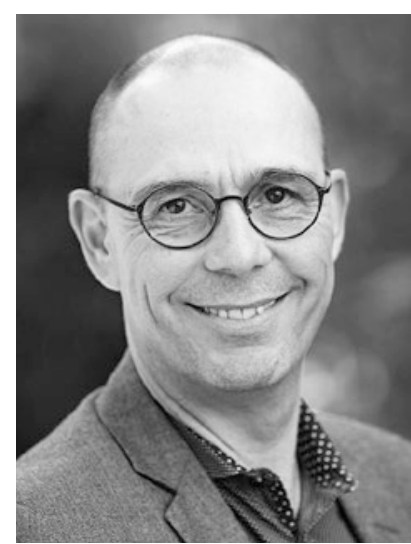

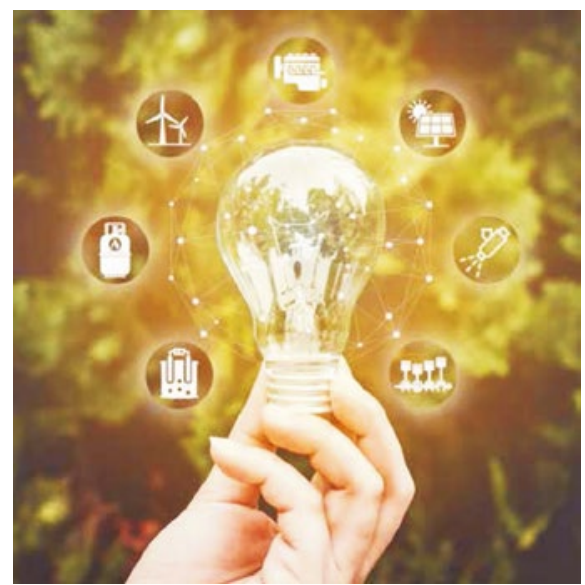

Wir möchten Ihnen die 12. Dessauer Gasmotoren-Konferenz mit dem Aufruf zur Einreichung von Vortragsthemen ankündigen.

\section{Themenschwerpunkte}

- zukünftige Gasmotorenkonzepte

- alle Arten von Gasmotoren für den Transport- und Industriesektor

- Aspekte der Konstruktion und Entwicklung von Gasmotoren und Gasmotorenzubehör

- Zündsysteme, Gemischbildung, Motorsteuerung, -überwachung, -diagnose, Aufladung, Abgasnachbehandlung

- alternative gasförmige Kraftstoffe z. B.

Wasserstoff, LNG, LPG, Biogas etc.

- Zuverlässigkeit, Betreibererfahrungen.

In einer konferenzbegleitenden Ausstellung haben Sie die Möglichkeit, Ihr Unternehmen sowie Produkte und Leistungen vorzustellen.

Die Konferenzsprachen sind Deutsch und Englisch mit Simultanübersetzung.

\section{TERMINE}

\section{August 2020}

Anmeldeschluss für die Einreichung der Abstracts (Anmeldeformular unter: www.wtz.de)

\section{Januar 2021}

Letzter Abgabetermin der druckfähigen Vortragsfassung

WTZ Motorentechnik GmbH Mühlenreihe 2a, 06862 Dessau-Roßlau E-Mail: Saack@wtz.de www.wtz.de 